\title{
Fraud and Misconduct in Publishing Medical Research
}

\section{Dya Eldin M. Elsayed, MD}

Department of Community Medicine, Faculty of Medicine, Alzaiem Alazhari University, Sudan

Corresponding Author: Dya Eldin M. Elsayed, MD; email: delsayed@aau.edu.sd

Received 12 March 2020

Accepted 9 June 2020

Published 30 June 2020

Production and Hosting by Knowledge E

(c) Dya Eldin M. Elsayed,

MD. This article is distributed under the terms of the

Creative Commons

Attribution License, which

permits unrestricted use and redistribution provided that the original author and source are credited.

Editor-in-Chief:

Prof. Mohammad A. M. Ibnouf

\section{Abstract}

One of the important feature of scientific research is scrutinizing truth. Investigators strive for honesty and integrity in all scientific communications. Candidly reported methods and procedures, data and results, and their publication status should reflect authenticity. Publication of fake data diverts the search from truth. The aim of studying human subjects should be advancing research and scholarship and not just the researcher's own career. Misconduct in medical research is any intentional deviation from acceptable ethical principles. Intentional misconduct is a serious observation, and misconduct such as falsification and fabrication of data and plagiarism are the most common fraud practices in medical research. Misconduct can occur at any stage of the research process; however, it particularly occurs in the results section of the research as researchers try to avoid negative findings. Data falsification occurs when investigators attempt to alter data to meet their own expectations. Falsification could involve altering data and results on research participants' record to fit research report. Data fabrication occurs when researchers report data that were completely constructed and never occurred when running the research. Plagiarism is using-either deliberate or inattentive-other researchers' ideas and words without clearly acknowledging the source of that information. Although fraud and misconduct have serious consequences, they are not uncommon among research publications in scientific journals. Institutions have to develop a mechanism to discover research misconduct and to prevent it. Editors and reviewers are required to introduce some commentaries in the regulations to impose sanctions on those found guilty of research misconduct.

Keywords: research, fraud, misconduct

\section{Introduction}

Advances in medical and health sciences, and indeed all fields of academic and scientific research, depend on the reliability of the research records. A key foundation of scientific research is the search for truth. Investigators strive for honesty and integrity in all scientific communications (data, results, methods and procedures, and publication status). 
Researchers, university staff and graduate students are expected to conduct their research in accordance with the highest ethical standards, adhering to all relevant institutional, national, and international guidelines. Conducting and reporting research ethically is a priority. Moreover, ethical conduct not only fulfils a moral imperative but also leads to better research results. Researchers should pay attention to the details of research, including quantitative and statistical techniques, and predictable collaboration among investigators. The credibility of the research process and the results depend on adherence to the highest ethical standards throughout the whole research process [1]. Publication of fake data diverts this search from the truth. When conducting research, the aim should be advancing research and scholarship, and not just advancing just one's career [2]. Intentional misconduct is considered a serious breach of scientific honesty and integrity.

Allusion to misconduct in scientific research has been made as early as in 1830 when the mathematician and inventor Charles Babbage (1791-1871) wrote about the unethical practices he had observed in scientific writing in Britain. He used terms such as 'Hoaxing', 'Forging', 'Trimming', and 'Cooking of Data'. According to Babbage, Hoaxing and Forging occur when one makes up data. Trimming occurs when one clips off pieces of data that do not agree with one's hypothesis, and Cooking occurs when one manipulates data to make them appear to be more accurate than they are [3].

In contemporary science and ethics, terms like Hoaxing, Forging, Trimming, and Cooking are replaced by falsification and fabrication of data and plagiarism. These are the most common fraud practices in medical research. Although, misconduct can occur at any stage of the research process, it particularly occurs in the results section when researchers attempt to avoid reporting negative findings [4].

Fraud and misconduct in scientific research appear to be on the rise among the scientific community throughout the whole world, with instances committed by individuals, institutions, and corporations alike [5]. The scientific community started to become concerned about research fraud and misconduct in the early 1980s. Prior to this, research institutions sometimes ignored or covered up potential misconduct rather than investigate it [6]. It should be noted, however, that research misconduct does not include an accidental error or honest misinterpretation of results and honest error or differences of opinion ${ }^{[7]}$.

Fraud and misconduct are the two terminologies often used to describe deviation from ethical principles in conducting or reporting the research. They are often used interchangeably. However, there is a gross distinction between the two. Misconduct/fraud is a violation of the ethical standard and/or codes of conduct in scientific research. "Fraud 
is an intentional deception made for personal gain or to damage another individual, for instance, intentionally falsifying and/or fabricating research data, and misleading reporting of the results." In contrast to fraud, which is intentionally committed, misconduct may not be an intentional action, rather an act of poor management including failure to follow predetermined protocols whenever the failure causes unreasonable risk or harm to humans.... so, fraud is usually deliberately committed. It should have an element of celebrate action, which is not the case with misconduct [8, 9]. However, in this article the author has used the term "research misconduct" to mean both fraud and misconduct.

Several studies have found that more than $40 \%$ of surveyed researchers were aware of misconduct but did not report it [9]. Sheehan et al. reported that $17 \%$ of surveyed authors of clinical drug trials reported that they personally knew of fabrication in research occurring over the previous 10 years [10].

The objective of this article is to present the most important types of research misconduct and fraud. To our knowledge many graduate students, young researchers, and even some researchers in universities and research centers are unfamiliar and unaware of the danger of research misconduct and fraud. The author wants to empower researchers with sufficient knowledge concerning research misconduct; hopefully this might help them avoid such misconduct whether deliberately or accidentally.

\section{Materials and Methods}

The author surveyed similar articles published in medical- and health-related journals regardless the place and time of publication using keywords such as "research misconduct," "fraud," "fabrication," "falsification and plagiarism." The purpose of the search was to find what has been written on the topic and how it has been written. Our search focused on history, definition, and common types of misconduct. It also includes the identification of ways to prevent research misconduct and fraud. Besides medical journals, the search covered books and periodicals of some scientific and research institutions.

During the research, the author obtained many publications covering the topic of our intended manuscript. Nineteen publications were eligible for the research misconduct. One of the publications was an online course on research misconduct, two were text books, and sixteen were journal articles published by individuals or a group of authors. Two of the articles were published by health institutions. 


\section{Common types of fraud in research}

Fabrication, falsification, plagiarism or deception in proposing, carrying out, or reporting results of research are the most common forms of fraud.

\subsection{Data falsification}

Sometimes the results of a study do not match the investigator's predictions. So, some investigators might modify these research results to improve the outcome and have reported results they "knew to be untrue" [9]. Falsification occurs when investigator attempts to alter data to meet theirown expectations. Falsification could involve altering data and results on research records to fit research report. For example, altering the results of interview, observation, or claiming to have performed a procedure on a research participant who had not undergone that procedure [11].

Examples of common forms of data falsification:

- Exchanging records for different research participants

- Falsely reporting that certain research team members, who were supposed to perform certain procedures during the research course, had done so when they had not; altering the dates of visits

- Altering the data on patients screening records and/or submitting the same records with mild or moderate altered dates on multiple occasions

- Failing to update the patients' status and representing data from prior screening or survey as being current

- Altering the results of particular tests on blood samples (or any biologic materials) to show that the test accurately predicted the disease under study

- Backdating follow-up interviews to fit the predetermined time by the study protocol.

\subsection{Fabrication}

Data fabrication occurs when the researcher reports data that was completely constructed and had never occurred during the course of the study. For example, reporting an interview that had never taken place or providing data on blood samples that were not taken. The researcher might also report data on patients who do not exist, insert fabricated data into medical records, or include progress data for a person who had 
died. Fabrication is more serious than any other form of fraud or misconduct. We could summarize data fabrication in the following points:

- Creating records of interviews, observation, or review of medical records that never took place

- Making up progress notes for patients who have not been visited or reporting records on patients who had already died.

The difference between fabrication and falsification is that fabricating data involves creating entirely new records, whereas data falsification involves altering existing records.

\subsection{Plagiarism}

In the course of research, it is advisable to review the available published literature. This allows the researcher to see what has already been done in the field, how it has been done, and to collect information that might help in creating new insights. Knowledge is built on previous publicly available knowledge, that is, we use each other's previous works as foundation for building new knowledge. However, it is equally important to give credit to the source of this information. Failure to acknowledge others' work can be classed as plagiarism. Plagiarism is the deliberate or inadvertent use of others' ideas and words without clearly acknowledging the source of that information [12]. The availability and ease of access to electronic information make using it easier. Unfortunately, open access to electronic media may contribute to the spread of plagiarism (copy/paste).

To avoid plagiarism, one should always cite the source when using ideas, opinions, facts, statistics, or any information that is not common knowledge (widely known facts). For example, the statement "research involving human subjects should be conducted by essential ethical principles" describes something that everyone knows. It is therefore common knowledge and does not require a citation and source reference. Contrastingly, content that is not common knowledge must have its source acknowledged and cited. For example, international ethical guidelines require some forms of informed consent in research with humans to ensure that research is informed, voluntary, and competent, thereby minimizing the chance of exploitation of study subjects (Coughlin) [13].

Other forms of research misconduct include unethical research. This is research that failed to fulfil some or all ethical values. Defective data description, Image manipulation, inadequate author, undeclared conflict of interest, and redundant publication are less serious. 


\section{Why does misconduct occur?}

An action is considered to be a misconduct when it represents a significant departure from accepted practices and has been committed intentionally, or recklessly. The motivating factors for research misconduct vary, however, ambition is one of the most common. University staff gain career advancement by conducting research and publishing. Some researchers want and hope for professional recognition within their institution and within the wider international scholarly community. It could also occur due to innocent ignorance or laziness of the investigators or other research staff, for complex studies needing repeated assessments for instance, repeating blood drawing or continuous monitoring (blood pressure, pulse or temperature readings). Misconduct may also occur when an investigator strongly believes intuitively in the "right" answer although the right answer may be contrary [4, 7, 8, and 13].

Cultural differences and personality and character issues are other factors that can influence the involvement of investigators in research misconduct. Usually, many people cheat, lie, or steal for money or financial interests. But in research, money may not be the prime motivator. Investigators may commit fraud for glory, for the desire to be the first and be famous and known as prominent investigator [10].

There could also be associated institutional factors such as the number of research studies at a time (workload), the existence of explicit versus implicit rules, penalties and rewards attached to such rules, training of investigators, regulations involved, and closed supervision. Also, lack of resources needed for ethical research conduct can foster misconduct [14].

To the best of our knowledge, there is no documented case of research misconduct in Sudan. However, in the international literature many cases were discussed. One of the prominent cases of publishing fabricated research is the case of Eric Poehlman from the University of Vermont in Burlington, USA. He had published fabricated research in 10 articles, each in a different journal. The case was investigated by the Office of Integral Research. He was found guilty and all fabricated research was retracted from the journals [2].

\section{How is misconduct identified?}

It is very important to identify misconduct. Warning signals, during the peer review of a research paper, should prompt the reviewer to be more vigilant and look at the data with a magnifying glass. The widespread phenomenon of research fraud makes us 
reconsider that it is appropriate to look at every article as suspect until proven otherwise. For example, a 100\% response rate and excessive instances of perfect attendance could be signs of falsified data. The most important identifiers include implausible trends, for example, in clinical trials, $100 \%$ drug compliance, identical laboratory results, no serious adverse events reported, and subjects adhering perfectly to a visit schedule can all be evidence that the results are being manipulated [15].

A good research study leads to further studies. Failure to reproduce and repeat a study by other investigators indicates fraud data. Failure to confirm research results by the researcher's laboratory or others is another indicator that could indicate research misconduct.

The current procedures for detecting misconduct in research, which are often discovered by chance, are not sufficient. Hence, more rigorous procedures are desperately needed. First, it is necessary to train researchers to avoid fraud and misconduct in medical research. It is their responsibility to conduct ethically sound research and to report misbehavior by colleagues.

\section{What to do when misconduct is discovered?}

Misconduct is a serious offence that requires effective and rapid reactions and sanctions against researchers who commit it. When an accusation or suspicion of fraud occurs, the institute or university must follow the institutional steps in determining the fraud. A thorough investigation is required. To determine the fraud, its type, who is responsible for its occurrence, how did it occur, and identifying its consequences are important. Once a case of fraud is established, first, the punishment should be determined and the research should be ceased, irrespective of the stage the study is, retracting the published papers from scientific journals and conference proceedings. Second, punishment may include reprimanding, rank, and salary reduction, and even the dismissal of persons involved in misconduct. In medical research with misconduct, junior employees may bear the burden of sanction for scientific misconduct [16-18].

\section{What is the possible impact of research misconduct?}

Adhering to proper ethical standards helps promote medical and health research, encourages public support, and reminds researchers of their accountability to the public. Misconduct can destroy the values of cooperation and collaborative work between colleagues and partners, and also undermine moral and social values [19]. Misconduct 
in medical- and health-related research affects the validity of data and impacts adversely the core of good clinical practice by threatening the rights, safety, and well-being of research participants. On a broader scale, it can lead to wrong, ineffective, or even harmful medical practices and pharmaceutical products [21]. Misconduct can give a bad name to the university or research institution and might result in funding and sponsorship cuts [20].

\section{Mechanisms to prevent misconduct}

\subsection{Primary and secondary prevention}

Prevention of research misconduct requires certain characters and procedures. Mechanisms to preventing research misconduct can include primary as well as secondary measures. Primary prevention aims at identifying and removing causes of misconduct prior to its occurrence. First, the author thinks that the establishment of guidelines and regulations would help a lot to prevent research misconduct. They should be steeled at institutional and national levels. Regulations should include articles on punishment for misconduct. Second, joiner investigators and graduate students should receive appropriate training in both research methodology and research ethics. Third, thorough review of submitted manuscripts should be done. Editors may ask specialists to review manuscripts prior to acceptance. Reviewers can make use of Internet and available technologies to review and compare submitted manuscripts with previously published literature. Editors won't publish when misconduct is discovered. Fourth; investigators should be required to share data, results, ideas, tools, resources with colleagues, senior as well as junior. Colleagues should help one another to discover mistakes including misconduct and the investigators should be open to criticism and new ideas. Finally, for the secondary prevention of research misconduct, that is, early detection and discovery of cases of misconduct, each suspected case should be investigated and sanctions be delivered to those revealed to be responsible for the misconduct. Sanctions involve retraction of fraudulent articles and punishment to those found guilty of fraud [21]

\section{National Rules and Regulations}

The foundations, controls, and standards that define the levels of health services and health research in the Republic of the Sudan are the responsibility of the Federal Ministry 
of Health $(\mathrm{FMOH})$ and the institutions affiliated with the organ [22]. For research governance, the FMOH has established the "National Health Research Ethics Committee," which has developed the National Guidelines for Research Ethics (2008 amended 2017). At the national level, Sudan has established the "National Board for Medicines and Poisons," which is responsible, among other responsibilities, for clinical trials. Yet, none of the two national bodies has designed a system for evaluating allegations of scientific fraud.

The author believes that at this time, with the spread of fraud in medical research, we need to create a national body for research integrity that is concerned with medical research issues and establish a system for identifying and evaluating fraudulent research and punish researchers who commit research misconduct $[23,24]$

\section{Conclusion}

Fraud and misconduct, if not identified, have serious consequences. They may lead investigators to the wrong directions if they cite and use such published fraud data. Bad consequences can also extend to the management of patients and science.

Universities and research institutions are required to develop a mechanism to discover and prevent fraud in research. Institutional and national research ethics guidelines in Sudan do not prescribe specific sanctions on those found guilty. So, institutions are required to introduce some articles in the regulations to impose sanctions on those found guilty of research misconduct.

\section{The author would also like to recommend the following:}

1. Creating a national body (like an office) for research integrity

2. Training on research ethics, research integrity, and research misconduct has to be integrated into the curriculum of undergraduate and postgraduate students

3. Provision of training on research ethics should be made for in-service training of researchers

4. Conducting research studies aimed at determining the occurrence of scientific misconduct among academic researchers in Sudan

5. Research misconduct committees should have preventive as well as investigative roles 


\section{Acknowledgement}

The author would like to thank Professor Suad Suliman for her assistance in developing this work. She revised and corrected the early draft.

\section{Conflict of Interest}

The author declares that there is no conflict of interest.

\section{References}

[1] Shahnazarian, D., Rose, S. L., Hagemann, J., et al. Avoiding being penalized: research misconduct. USC online course. Retreived from: www.citiprogram.org [accessed April 1, 2016].

[2] Sox, H. C. and Rennie, D. (2006). Research misconduct, retraction, and cleansing the medical literature: lessons from the PoehIman case. Annals of Internal Medicine, vol. 144, no. 8, pp. 609-613.

[3] Baggage, C. (1970 \{1830\}). Reflections on the Decline of Science in England. New York, N.Y.: Andesite Press.

[4] Weir, C. and Murray, G. (2011). Fraud in clinical trials: detecting it and preventing it. Significance, pp. 164-168.

[5] Catano, V. M. and Turk, J. (2007). Fraud and misconduct in scientific research: a definition and procedures for investigation. Med Law, vol. 26, no. 3, pp. 465-476.

[6] Institute of Medicine, National Academy of Sciences, and National Academy of Engineering. "Research Misconduct." On Being a Scientist, chapter 6. Retrieved from: http://www.nap.edu/read/12192/ [accessed April 12, 2016].

[7] US Department of Health. Definition of research misconduct. Retrieved from: http://ori.hhs.gov/definition-misconduct [accessed March 30, 2016].

[8] Bhatt, A. (2011). Quality of clinical trials: a moving target. Perspectives in Clinical Research, vol. 2, pp. 124-128.

[9] Gupta, A. (2013). Fraud and misconduct in clinical research: a concern. Perspectives in Clinical Research, vol. 4, no. 2, pp. 144-147.

[10] Sheehan, J. G. (2007). Fraud, conflict of interest, and other enforcement issues in clinical research. Cleveland Clinic Journal of Medicine, vol. 74, pp. S63-S67.

[11] Elsayed, D. M. (2013). Manual for Research Ethics in Medical and Health Sciences. Saarbrücken, Germany: Lap Lambert Academic Publishing. 
[12] Das, N. and Panjabi, M. (2011). Plagiarism: Why is it such a big issue for medical writers? Perspectives in Clinical Research vol. 2, no. 2, pp. 67-71.

[13] Kumar, P. M., Priya, N. S., Musalaiah, S., et al. (2014). Knowing and avoiding plagiarism during scientific writing. Annals of Medical and Health Sciences Research, vol. 4, no. 3, pp. S193-S198.

[14] Habermann, B., Broome, M., Pryor, E. R., et al. (2010). Research coordinators' experiences with scientific misconduct and research integrity. Nursing Research, vol. 59, no.1, pp. 51-57.

[15] Jessen, J., Robinson, E., Bigaj, S., et al. (2007). Unreported clinical research fraud and misconduct. Journal of Clinical Research Best Practices, vol. 3, no. 1, pp. 1-5.

[16] Reynolds, S. M. (2004). ORI findings of scientific misconduct in clinical trials and publicly funded research, 1992-2002. Clin Trials, vol. 1, no. 6, pp. 509-516.

[17] Fanelli, D. (2009). How many scientists fabricate and falsify research? A systematic review and meta-analysis of survey data. PLOS ONE, vol. 4, no. 5, p. e5738.

[18] Elsayed, D. M. and Elamin, R. (2009). Medical ethics: what is it? Why is it important? Slovenian Journal of Public Health, vol. 4, no. 2, pp. 284-287. Retrieved from: http: //www.sjph.net.sd

[19] Al-Marzouki, S., Roberts, I., Marshall, T., et al. (2005). The effect of scientific misconduct on the results of clinical trials: a Delphi survey. Contemporary Clinical Trials, vol. 26, pp. 331-337.

[20] Ghooi, R. B. (2014). Expert committee to formulate policy and guidelines for approval of new drugs, clinical trials and banning of drugs-comments. Perspectives in Clinical Research, vol. 5, no. 3, pp. 100-107.

[21] Weed, D. L. (1998). Preventing scientific misconduct. American Journal of Public Health, vol. 88, no. I, pp. 125-129.

[22] Sudan: National Public Health Law of 2008.

[23] Eldin Mohammed Elsayed, D. (2006). National framework for ethics in health research involving human subjects. Sudanese Journal of Public Health, vol. 1, no. 3, pp. 192 196. Retrieved from: http://www.sjph.net.sd

[24] Eldin Mohammed Elsayed, D. (2007). National health research system: for better health. J.c. Tech, vol. 8, no. 1, pp. 88-96. 